\title{
Thermodynamic Justification for the Ni/Al/Ni Joint Formation by Diffusion Brazing
}

\author{
W. S. Wołczyński* ${ }^{1}$, T. Okane ${ }^{2}$, C. Senderowski ${ }^{3}$, D. Zasada ${ }^{3}$, B. Kania ${ }^{4}$, J. Janczak-Rusch ${ }^{5}$ \\ ${ }^{1}$ Institute of Metallurgy \& Materials Science, Polish Academy of Sciences, Reymonta 25, 30059 Kraków, Poland \\ ${ }^{2}$ AIST - National Institute of Advanced Industrial Science \& Technology, Umezono 1-1-1, 3058568 Tsukuba, Japan \\ ${ }^{3}$ Military University of Technology, Kaliskiego 2, 00-908 Warszawa, Poland \\ ${ }^{4}$ AGH - University of Science \& Technology, Reymonta 19, 30-059 Kraków, Poland \\ ${ }^{5}$ EMPA-Swiss Federal Laboratories for Materials Science \& Technology, Ueberland 129, 86000 Duebendorf, Switzerland \\ *nmwolczy@imim-pan.krakow.pl
}

\begin{abstract}
A theoretical model for the joint formation was developed for diffusion brazing. The phenomena of dissolution and solidification were included into the model. A thermodynamic justification for the isothermal brazing occurrence in the meta-stable conditions was developed. It involved the application of the criterion of higher temperature of the solid / liquid (s/l) interface. The dissolution of the filler metal in the substrate was described by the $N_{0}-$ solute concentration within the dissolution zone (liquid film) situated at the substrate surface. The selection of the $N_{0}-$ parameter was justified by the Thermocalc calculation of the Ni-Al phase diagram for meta-stable equilibrium. According to the model assumptions, the solidification was accompanied by undercooled peritectic reactions resulting in formation of intermetallic phases. The average $\mathrm{Al}$ - solute concentration measured across a given $\mathrm{Al}_{3} \mathrm{Ni}_{2} / \mathrm{Al}_{3} \mathrm{Ni}_{1} / \mathrm{Al}_{3} \mathrm{Ni}_{2}$ joint confirmed that the $N_{0}$ - solute concentration was conserved within the joint sub-layers. The Ni-Al phase diagram for meta-stable equilibrium referred to for the solidification was also calculated by means of the Thermocalc Software. It allowed to locate the solidification path, s/l interface path and redistribution path onto the mentioned diagram. Superposition of both calculated phase diagrams was also given to show that the joint formation occurred cyclically under the meta-stable conditions. Isothermal formation of the $\mathrm{Ni} / \mathrm{Al} / \mathrm{Ni}$ joints has been performed at different temperatures. The following $T_{R}$ - temperatures have been applied: 700, 750, 800, 850, 900, 950 , and $1000{ }^{\circ} \mathrm{C}$. The solidification was arrested and the actual morphologies frozen. It allowed to make a measurement of the $\mathrm{Al}$ - solute concentration across each joint by means of the EDX micro-analyzer to estimate average solute concentration, $\bar{N}_{0}$. Regardless of the $T_{R}$ - temperature, the solidification path was always the same.
\end{abstract}

Keywords: : meta-stable equilibrium, joint formation model, dissolution, solidification

\section{Introduction}

A solidification, a dissolution and some solid/solid transformations are predicted by Tuah-Poku et al., (1988) as phenomena which are to be observed during diffusion brazing.

The solidification and dissolution are subjected to consideration in the current model. However, exceptionally the first solid / solid transformation is strictly connected with solidification and dissolution through the mass balance (Kloch et al., 2005).

A dissolution of substrate by the liquid filler metal occurs continuously within a zone $d x$, Figure 1 . The dissolution prepares the liquid film within the zone $d x$. Once the zone becomes liquid the mass of this liquid film diffuses towards the joint symmetry axis and solidification occurs at the s/l interfaces, (Wołczyński et al., 2006a).

Solidification is accompanied by the undercooled peritectic reactions, Figure 2. According to the concept of Chuang et al. (1975), undercooled peritectic reactions take place at the solid/liquid ( $\mathrm{s} / \mathrm{l})$ interface.

The occurrence of peritectic reactions at the s/l interface of cells formed within a given sub-layer are marked schematically with some arrows in Figure 2.

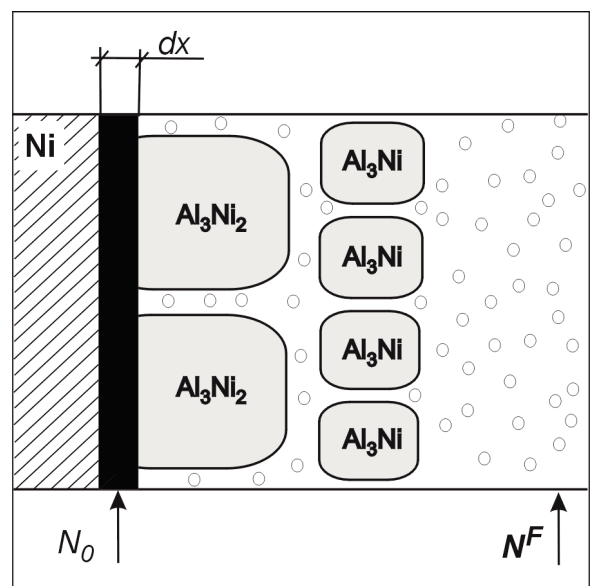

Figure 1. Ni-substrate dissolution within its infinitesimally small amount, $d x$ (the so-called zone $d x$ situated just at the substrate surface) due to diffusion of liquid solution of the filler metal, $N^{F}$, through the channels situated among some cells of $\mathrm{Al}_{3} \mathrm{Ni}_{2}$ or $\mathrm{Al}_{3} \mathrm{Ni}$ phases formed in a given sub-layer, respectively. A reaction within the zone is as follows: liquid $\left(N^{F}\right)+N i \rightarrow$ undercooled liquid $\left(N_{0}\right)$. 
The internal channels within cells are mainly employed for the flow of dissolved substrate towards the $\mathrm{s} / 1$ interfaces (bulk diffusion). The dissolved substrate contained within zone $d x$ has the solute concentration equal to $N_{0}$, Figure 1 .

Under the described conditions, a bonding process can result in a joint that reproduces micro-structurally a sequence of inter-metallic compounds or phases as it is visible in an adequate phase diagram for stable equilibrium, (Jacobson and Humpston, 1992; Wołczyński et al., 2006b).

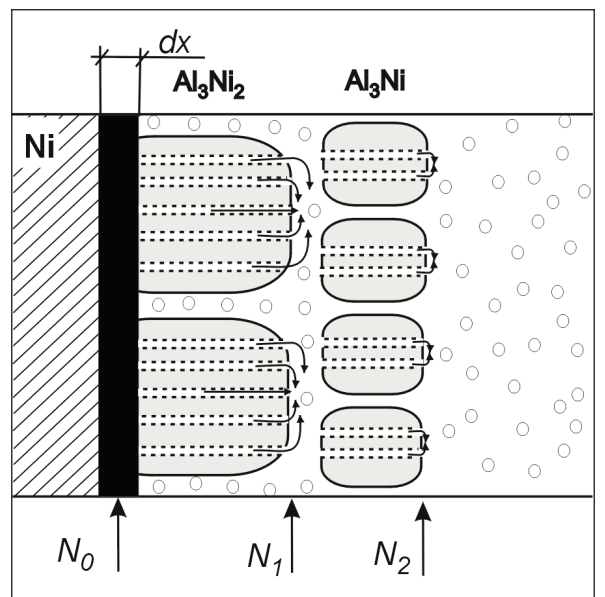

Figure 2. The undercooled peritectic reactions at the front of cells (as it results from the phase diagram for stable equilibrium): $N_{1}$ - solute concentration within undercooled liquid for the first peritectic reaction resulting in formation of the sub-layer that contains cells of the $\mathrm{Al}_{3} \mathrm{Ni}_{2}$ intermetallic phase, $\mathrm{N}_{2}$ - solute concentration within undercooled liquid for the second peritectic reaction resulting in formation of the sub-layer that contains cells of the $\mathrm{Al}_{3} \mathrm{Ni}$ intermetallic compound. The channels predicted in the model for bulk diffusion are shown schematically and completed with some arrows that signify occurrence of a given peritectic reaction.

The analysis is focused on the formation of the $\mathrm{Ni} / \mathrm{Al} / \mathrm{Ni}$ joints in relation to the diffusion brazing. It makes it possible to develop a description for the solidification preceded by the dissolution and a new explanation for the role of the solidification path for the creation of the joint sub-layers.

Additionally, a thermodynamic justification for the beginning of solidification path, $N_{0}$ and the end of solidification path, $N^{F}$, are both given. The Thermocalc calculation of the $\mathrm{Ni}-\mathrm{Al}$ phase diagram for meta-stable equilibrium will give the grounds for this justification.

\section{Solidification / dissolution model for the formation $\mathrm{NiAl}_{3} \mathrm{Ni}_{2} / \mathrm{Al}_{3} \mathrm{Ni} / \mathrm{Al}_{3} \mathrm{Ni}_{2}-\mathrm{Ni}$ joint}

The system selects one and only one nominal concentration of the solute, $N_{0}$ at a given temperature, $T_{R}$, (Kloch et al., 2005). The selection of the $N_{0}$ - parameter by the system occurs in such a way to ensure the film, $d x$ (zone $d x$ ), to be liquid. The zone $d x$ is created at the surface of a substrate, Figure 1. It is evident that the liquid layer, $d x$, is strongly undercooled from its liquidus temperature. Thus, dissolution occurs at a given temperature, $T_{R}$, as long as it is necessary to transform solid substrate zone, $d x$, into the liquid film, $d x$.

Once the $d x$ zone becomes liquid and its concentration achieves a selected $N_{0}$, the undercooled liquid film is ready to be subjected to solidification involving undercooled meta-stable peritectic reactions, Figure 2.

The average Al-solute content measured within the $\mathrm{Ni} / \mathrm{Al} / \mathrm{Ni}$ joint obtained after different periods of time is always equal to the $N_{0}$ - concentration. Thus, the $N_{0}$ parameter is situated on the liquidus line as the beginning of solidification path, Figure 3.

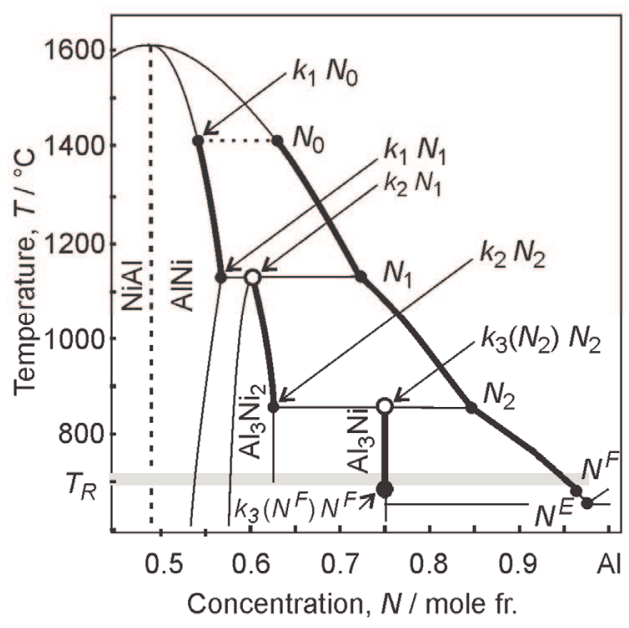

Figure 3. Ni-Al phase diagram for stable equilibrium with the $N_{0} \rightarrow N_{1} \rightarrow N_{2} \rightarrow N^{F}$ solidification path and with the $k_{1} N_{0} \rightarrow k_{1} N_{1} \rightarrow k_{2} N_{1} \rightarrow k_{2} N_{2} \rightarrow k_{3}\left(N_{2}\right) N_{2} \rightarrow k_{3}\left(N^{F}\right) N^{F}$ "historical" solid / liquid interface path. $T_{R}=700{ }^{\circ} \mathrm{C}$, and $N_{0}=0.64$ [mole fr.].

According to the current model assumption, the constant partitioning is justified for the formation of an intermetallic phase. In the case of an inter-metallic compound formation a varying partition ratio is to be applied. Thus, the universal definition of the $k$-partition ratio was introduced:

$k_{i}\left(N_{i}^{L}\right)=k_{i}^{0}+k_{i}^{L} N_{i-1} / N_{i}^{L} \quad 1, \ldots, n$,

As the assumed peritectic reaction $x_{i}+$ liquid $\left(N_{i}\right) \rightarrow$ $\left[x_{i}^{\max }-x_{i}^{\text {min }}\right]$ occurs during solidification, the amount of the primary phase is to be defined accordingly.

$x_{i}\left(\alpha_{i}^{D}, l_{i}^{0}, N_{i-1}, N_{i}, k_{i}\right)$
$\quad=l_{i}^{0}\left[\left(1-\left(N_{i} / N_{i-1}\right)^{\left(1-\alpha_{i}^{D} k_{i}\right) /\left(k_{i}-1\right)}\right) /\left(1-\alpha_{i}^{D} k_{i}\right)\right]$

Eq. (1) is universal and can be applied to the descriptions of a peritectic reaction when: a/ an intermetallic phase is formed, then $k_{i}^{L}=0$; and, b/ an intermetallic compound is formed, then $k_{i}^{L} \neq 0$ and the use of Eq. (1) in its full form is recommended. The $x_{i}^{\max }$ and $x_{i}^{\text {min }}$ - parameters have already been defined in detail, (Wołczyński et al., 2006a). Finally, the model allows determination of the ratio of sub-layers thickness, $\lambda_{1}^{K} / \lambda_{2}^{K}=$ $x_{1}^{\max } /\left(x_{2}^{\max }+x_{3}\right)$, Figure 4 , with some explanations shown in Figure 5.

According to the current model, the solute concentration within a given sub-layer should be the same as the solute concentration at the peritectic point in the phase diagram.

Thus, the Al solute concentration equals 60 at. $\%$, for the $\mathrm{Al}_{3} \mathrm{Ni}_{2}$ - intermetallic phase and 75 at.\% for the $\mathrm{Al}_{3} \mathrm{Ni}-$ intermetallic compound. 


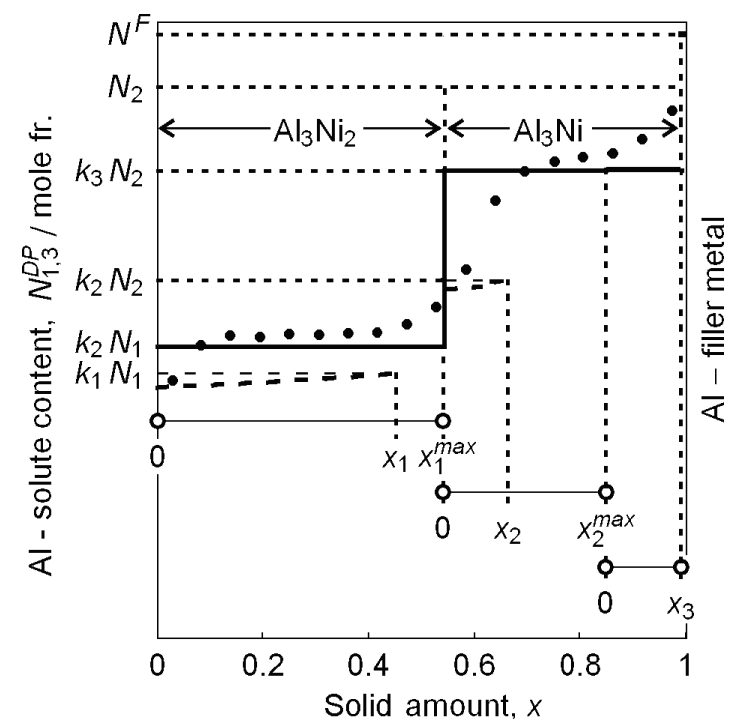

Figure 4. Reproduction of the sub-layers thickness ratio together with the measured solute redistribution profile (dots) resulting from the undercooled peritectic reactions. Profiles are mirrored across the centerline of the joint (dotted line): $\mathrm{Ni} / \mathrm{Al}_{3} \mathrm{Ni}_{2} / \mathrm{Al}_{3} \mathrm{Ni} / \mathrm{Al}_{3} \mathrm{Ni} \mathrm{i}_{2} / \mathrm{Ni}$. The ratio of sub-layers thickness is reproduced for the solidification path $N_{0} \rightarrow N^{F}$ shown in Figure 3. The measurement points (dots) are taken from the EDX analysis. Solidification was carried out at $700{ }^{\circ} \mathrm{C}$ for 121 [s].

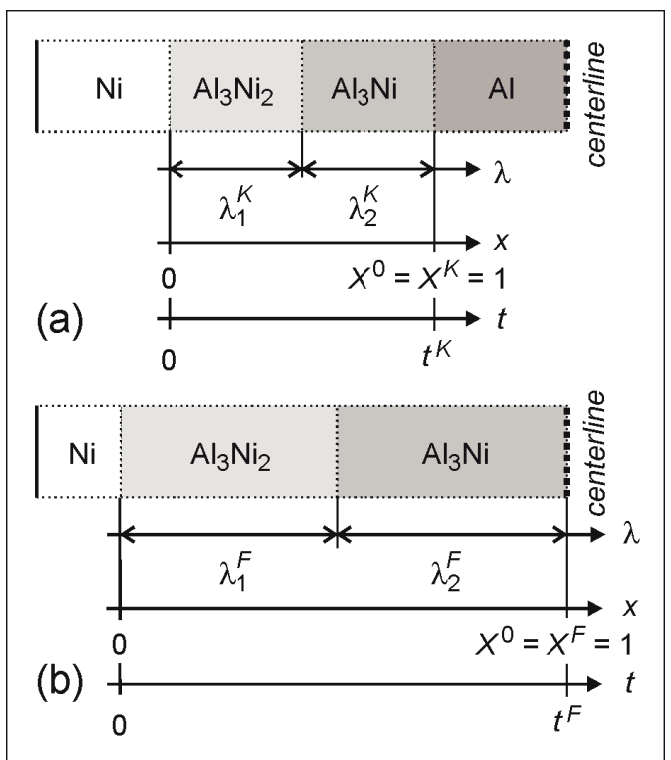

Figure 5. The meaning of some parameters in solidification of the $\mathrm{Al}_{3} \mathrm{Ni}_{2} / \mathrm{Al}_{3} \mathrm{Ni}$ multilayer on the Ni-substrate shown at: a/ a given step of the $\mathrm{Al}_{3} \mathrm{Ni}_{2} / \mathrm{Al}_{3} \mathrm{Ni}$ multi-layer formation; and, b/ completion of the $\mathrm{Al}_{3} \mathrm{Ni}_{2} \quad / \mathrm{Al}_{3} \mathrm{Ni}$ multilayer formation.

Thus, it will be verified whether the ratio of sub-layers thickness depends on the real temperature, $T_{R}$, at which the experiment is performed.

\section{Experimental verification of the current model for solidification/dissolution}

A set of experiments was carried out in order to study the sequence of the intermetallic sub-layers formation. The experiment of the $\mathrm{Ni} / \mathrm{Al} / \mathrm{Ni}$ diffusion joint formation was performed at different temperatures: 700, 750, 800, 850,
900, 950 and $1000{ }^{\circ} \mathrm{C}$.

An Al-foil $25 \mu \mathrm{m}$ thick was located between two pieces of nickel then tightened. The $\mathrm{Ni} / \mathrm{Al} / \mathrm{Ni}$ system was put into a vacuum furnace, then heated until a given temperature.

At each of the imposed temperatures, the Al-foil was melted and the system subjected to dissolution / solidification. The solidification was halted after a given period of time and the morphology of the interconnections was frozen, Figure 6.

The Al-solute segregation profiles were analyzed across the frozen interconnections by means of the EDX - microanalyzer. Next, an average content of the Al-solute, $\widehat{N}_{0}$, was determined for each of the studied joints. The estimated results are gathered in Table 1.

Since the values of the $\widehat{N}_{0}$ - parameter (Table 1) are similar to each other, the average Al - solute content, denoted as $\bar{N}_{0}$, and representative for all investigated joints was calculated. It is equal to $\bar{N}_{0} \approx 0.64$ [mole fr.], $\left(\bar{N}_{0} \cong\right.$ $\left.(1 / 7) \sum \widehat{N}_{0}\right)$

The revealed interconnections morphology proved that the ratio of sub-layers thickness does not change with the $T_{R}$ - temperature imposed in a given experiment. This conclusion does not result directly from the ratio of areas marked for sub-layers visible in Figure 6a., and Figure 6b.

It was necessary to correct the thickness of the $\mathrm{Al}_{3} \mathrm{Ni}$ phase sub-layers as follows:

a/ in the case when the areas of the $N^{F}$ solution exist inside the sub-layer, the thickness of the $\mathrm{Al}_{3} \mathrm{Ni}$ phase sub-layers is to be diminished. The diminution is required since the $N^{F}$ solution did not yet transform into the joint. It is clearly visible in Figure 6a.

$\mathrm{b} / \mathrm{in}$ the case, when the areas of the pure $\mathrm{Al}$ exist inside the sub-layer, the thickness of the $\mathrm{Al}_{3} \mathrm{Ni}$ phase sublayers is to be enlarged and the thickness of the $\mathrm{Al}_{3} \mathrm{Ni}_{2}$ phase sub-layer diminished adequately. It is required since the presence of pure $\mathrm{Al}$ located inside the $\mathrm{Al}_{3} \mathrm{Ni}$ phase sub-layers is the product of the so-called "mantis phenomenon". The phenomenon is described by the reaction which is as follows: $2 \mathrm{Al}_{3} \mathrm{Ni} \rightarrow \mathrm{Al}_{3} \mathrm{Ni}_{2}+$ $3 \mathrm{Al}$.

It was evident that the above reaction (if it occurred) diminished slightly the $\mathrm{Al}_{3} \mathrm{Ni}$ phase sub-layers and thickened a little the $\mathrm{Al}_{3} \mathrm{Ni}_{2}$ phase sub-layer. It is visible in Figure $6 b$.

Therefore, the adequate corrections were made while analyzing the ratio of thicknesses of both sub-layers.

It should be emphasized that according to the mass balance the average solute content, $\bar{N}_{0}$, revealed in the frozen interconnections is to be equal to the initial solute content, $N_{0}$, from which the interconnections were formed during solidification accompanied by the peritectic reaction.

The experiments allowed the identification of the intermetallic compound / phase sub-layers, Figure 6.

The areas which contains the $N^{F}$ - solution were identified in the case of the joint visible in Figure 6a.

The pure $\mathrm{Al}$ - areas resulting from the so-called "mantis phenomenon" revealed by Wołczyński et al. (2006b) (full consumption of the $\mathrm{Al}_{3} \mathrm{Ni}$ compound by the $\mathrm{Al}_{3} \mathrm{Ni}_{2}-$ dominant phase) and described adequately by the reaction $2 \mathrm{Al}_{3} \mathrm{Ni} \rightarrow \mathrm{Al}_{3} \mathrm{Ni} i_{2}+3 \mathrm{Al}$ were also identified in the case of the current analysis, Figure $6 \mathrm{~b}$.

The suggested reaction occurs just after completion of the solidification. This is the result of the system tendency towards thermodynamic equilibrium (towards the formation 
of all the phases visible in the $\mathrm{Ni}-\mathrm{Al}$ phase diagram in sequence: $\mathrm{Al}_{3} \mathrm{Ni}_{2}, \mathrm{AlNi}, \mathrm{NiAl}, \mathrm{Ni}_{3} \mathrm{Al}$ and finally towards the exclusive existence of the (Ni) solution).

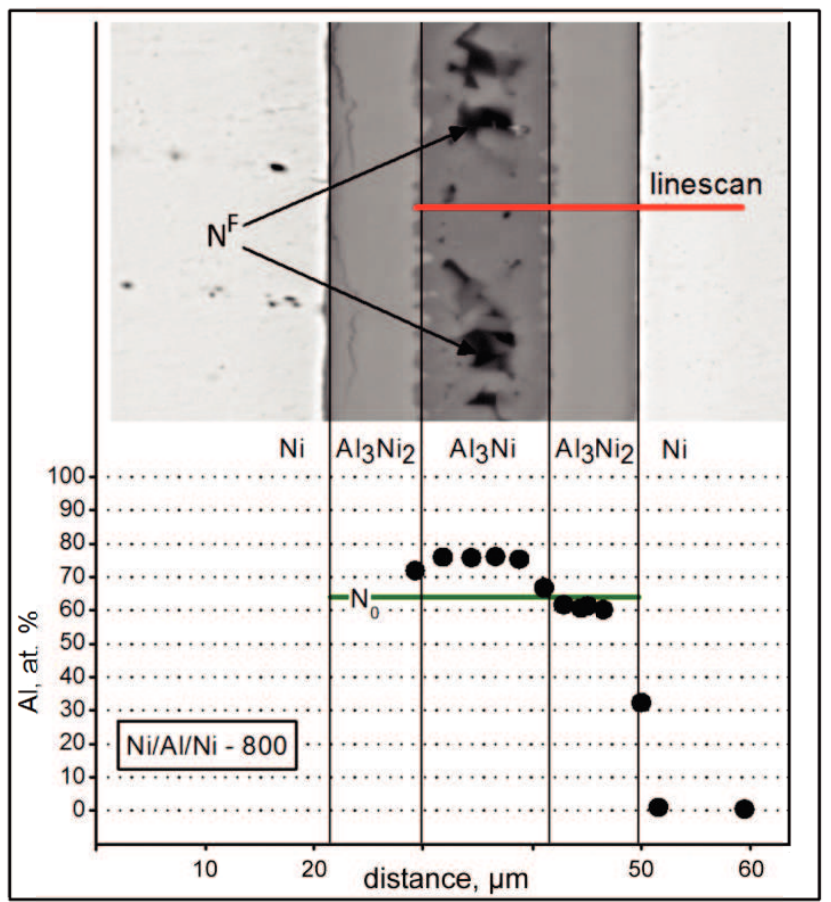

Figure 6a. The $\mathrm{Ni} / \mathrm{Al}_{3} \mathrm{Ni}_{2} / \mathrm{Al}_{3} \mathrm{Ni} / \mathrm{Al}_{3} \mathrm{Ni} \mathrm{i}_{2} / \mathrm{Ni} \mathrm{Ni} / \mathrm{Al} / \mathrm{Ni}$ joint morphology, $\left(T_{R}=800{ }^{\circ} \mathrm{C}\right)$, as observed at time $t<t^{F}$; the $\widehat{N}_{0}$ - parameter is estimated; time $t<t^{F}$ means that solidification was not yet completed and some areas of the $N^{F}$ - solution exists inside the $\mathrm{Al}_{3} \mathrm{Ni}$ sub-layer.

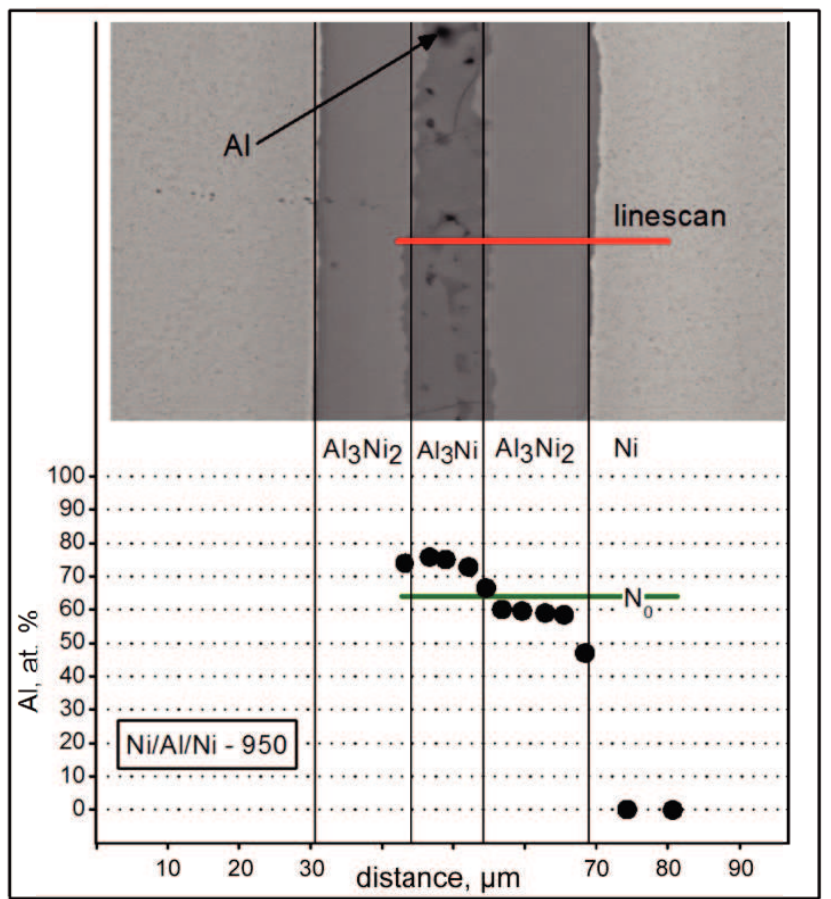

Figure 6b. The $\mathrm{Ni} / \mathrm{Al}_{3} \mathrm{Ni}_{2} / \mathrm{Al}_{3} \mathrm{Ni} / \mathrm{Al}_{3} \mathrm{Ni}_{2} / \mathrm{Ni} \mathrm{Ni} / \mathrm{Al} / \mathrm{Ni}$ joint morphology, $\left(T_{R}=950{ }^{\circ} \mathrm{C}\right)$, as observed at time $t>t_{M}$; the $\widehat{N}_{0}$ - parameter is estimated; time $t>t_{M}$ means that solidification was completed and the first solid / solid transformation occurred partially.
Table 1. Estimated values of the Al-solute content, $\widehat{N}_{0}$, within the Ni/Al/Ni joints formed at different temperatures $T_{R}$ due to solidification arrested at time, $t$, with $t<t^{F}$.

\begin{tabular}{|c|c|}
\hline$T_{R}\left[{ }^{0} \mathrm{C}\right]$ & $\widehat{N}_{0}[$ at. \%] \\
\hline 700 & 63.5 \\
\hline 750 & 63.6 \\
\hline 800 & 65.7 \\
\hline 850 & 66.5 \\
\hline 900 & 64.5 \\
\hline 950 & 63.7 \\
\hline 1000 & 62.5 \\
\hline
\end{tabular}

In the case of the current analysis, the first step of this tendency is visible in Figure 6a (formation of the $\mathrm{Al}_{3} \mathrm{Ni}$ phase and $\mathrm{Al}_{3} \mathrm{Ni}_{2}$ phase only).

The system begins to approach endeavor the thermodynamic equilibrium in the case of the joint shown in Figure 6b.

\section{Meta-stable condition for the joint formation}

$N_{0}$ - parameter localization on the liquidus line, as shown in Figure 3, indicates that the AlNi phase should be formed as the first sub-layer just at the substrate surface. Meanwhile, some experimental observations confirm the formation of the $\mathrm{Al}_{3} \mathrm{Ni}_{2}$ phase sub-layer but $\mathrm{AlNi}$ phase does not appear during the experiments, Figure 6 .

It is evident that the solidification occurred under metastable conditions since the AlNi phase was not formed.

The transition of the system from stable conditions to meta-stable conditions can be justified by means of the Umeda-Okane-Kurz criterion, (Umeda et al. 1996).

The schematically drawn $\mathrm{Ni}-\mathrm{Al}$ phase diagram for stable equilibrium is shown in Figure 7.

The characteristic $\bar{N}_{0}=N_{0}$ - solute content is also situated on the phase diagram. The intersections of the $N_{0}$ content with both meta-stable solidus lines defines $T_{f}^{*}$ temperatures of the $\mathrm{s} / \mathrm{l}$ interface for both discussed phases.

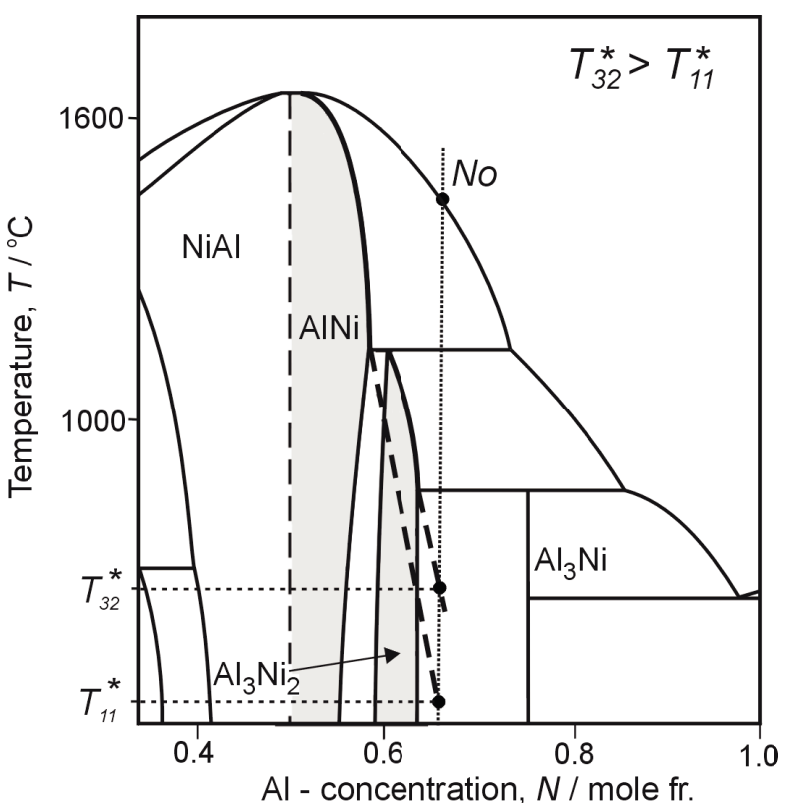

Figure 7. Application of the Umeda-Okane-Kurz criterion to the Ni-Al phase diagram for stable equilibrium. Two meta-stable solidus lines are added: first - for AlNi phase and second - for $\mathrm{Al}_{3} \mathrm{Ni}_{2}$ phase to explain a competition between the phases appearance during solidification. 
According to the mentioned criterion, this phase is formed which manifests a higher temperature of its $\mathrm{s} / 1$ interface during solidification. In the case of the $\mathrm{Ni}-\mathrm{Al}$ system $T_{32}^{*}>T_{11}^{*}$ as visible and written in Figure 7. Therefore, the $\mathrm{Al}_{3} \mathrm{Ni}_{2}$ phase formation is selected by the system instead of expected $\mathrm{AlNi}$ phase formation. Temperature $T_{11}^{*}$ results from the intersection of the metastable solidus line for the AlNi - phase (upper dashed line in Figure 7) and $N_{0}$ - solute concentration line (dotted line). Temperature $T_{32}^{*}$ results from the intersection of the meta-stable solidus line for the $\mathrm{Al}_{3} \mathrm{Ni}_{2}$ - phase (lower dashed line in Figure 7.) and $N_{0}$ - solute concentration line (dotted line).

Additionally, some calculations made by means of the Thermocalc Software allowed some Ni-Al phase diagrams for meta-stable equilibrium to be reproduced as follows:

a/ for a dissolution, Figure 8,

b/ for a solidification resulting in formation of both observed phases, Figure 9.

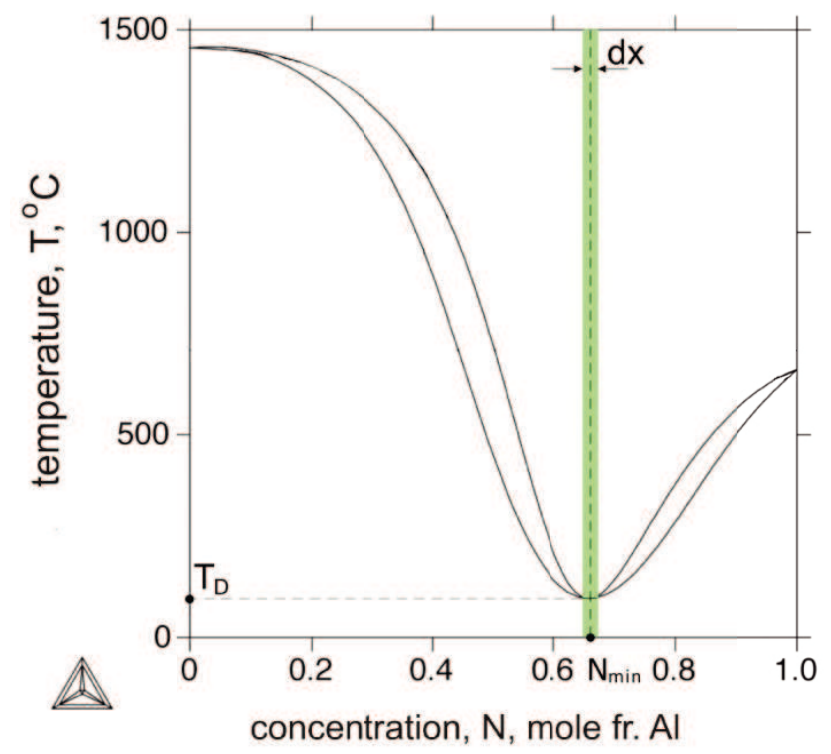

Figure 8. Ni-Al phase diagram for meta-stable equilibrium calculated for the solubility of Al (filler metal applied in the technology) in the Ni substrate. The upper line is the metastable liquidus and lower line is the meta-stable solidus.

The calculated phase diagram (meta-stable equilibrium) for the dissolution, Figure 8 , manifests the minimum at the Al-solute concentration $N_{\min } \approx 0.64$ [mole fr.].

It is evident that the $N_{\min }$ parameter value has the same meaning as the $N_{0}$ parameter value that represents the dissolution phenomenon in the model described by the scheme shown in Figure 1.

The minimum shown in Figure 8 defines the minimal temperature, $T_{D}$. At the $T_{D}$ - temperature the dissolution (described in Figure 1) occurs as easily as possible. In other words, the appearance of minimum suggests that even at the $T_{D}$ temperature the liquid solution can exist within the zone $d x$, Figure 1, under imposed meta-stable condition of the $\mathrm{Ni} / \mathrm{Al} / \mathrm{Ni}$ interconnection formation.

The phase diagram for dissolution is superposed onto the phase diagram for solidification in order to emphasize that both discussed phenomena occur cyclically, $N^{F} \rightarrow N_{0}$ (dissolution) and $N_{0} \rightarrow N^{F}$ (solidification), Figure 9.

The dissolution path, $N^{F} \rightarrow N_{0}$, begins at liquidus line of the meta-stable equilibrium phase diagram calculated for solidification and is completed at the liquidus line minimum of the meta-stable equilibrium phase diagram calculated for dissolution (dashed green line), Figure 9.

The solidification path $N_{0} \rightarrow N^{F}$, is situated on the liquidus line of the meta-stable equilibrium phase diagram calculated for the solidification, Figure 9.

The $N^{F}$ - concentrations shown in Figures 1, 3 6a were measured by means of the scanning electron microscopy equipped with the EDAX energy dispersive X-ray (EDX) microanalyzer, Figure 10a, $\left(N_{\text {exp }}^{F}\right)$. Next, it was determined theoretically, Figure $10 \mathrm{~b},\left(N_{\text {theor. }}^{F}\right)$. Additionally, solute concentration in the zones $s S$ and $s$ is determined for a given $T_{R}$ - isotherm.

The $N_{\text {theor. }}^{F}$ value was determined as the intersection of the $T_{T}$ - isotherm and liquidus line of the phase diagram for meta-stable equilibrium, Figure $10 \mathrm{~b}$.

The $s S$ - point results from the intersection of the $T_{R}-$ isotherm and solidus line which is drawn in the meta-stable equilibrium phase diagram calculated for dissolution, while $s$ - point is determined by solidus line of the meta-stable equilibrium phase diagram for solidification.

\section{Concluding remarks}

1/ Regardless of the real temperature, $T_{R}$, imposed in the technology, (Table 1), the beginning of the solidification path is always the same, and is equal to $N_{0}$.

2/ Regardless of the real temperature, $T_{R}$, the end of solidification path is always the same and is equal to $N^{F}$, which was confirmed experimentally, Figure 10a, and predicted theoretically, Figure 10b. Good agreement was obtained between both $N_{\text {exp }}^{F}$. and $N_{\text {theor. }}^{F}$ parameters.

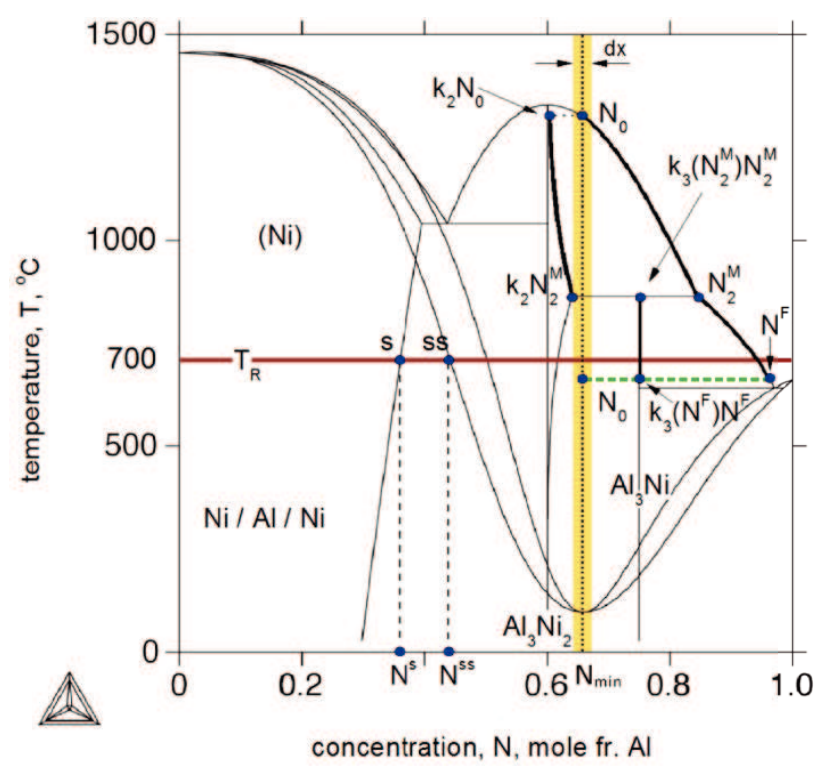

Figure 9. Superposition of the Ni-Al phase diagrams for meta-stable equilibrium calculated: a/ for the dissolution phenomenon discussed in Figure 8, and b/for solidification resulting in the $\mathrm{Ni} / \mathrm{Al}_{3} \mathrm{Ni}_{2} / \mathrm{Al}_{3} \mathrm{Ni} / \mathrm{Al}_{3} \mathrm{Ni}_{2} / \mathrm{Ni}$ joint formation. 

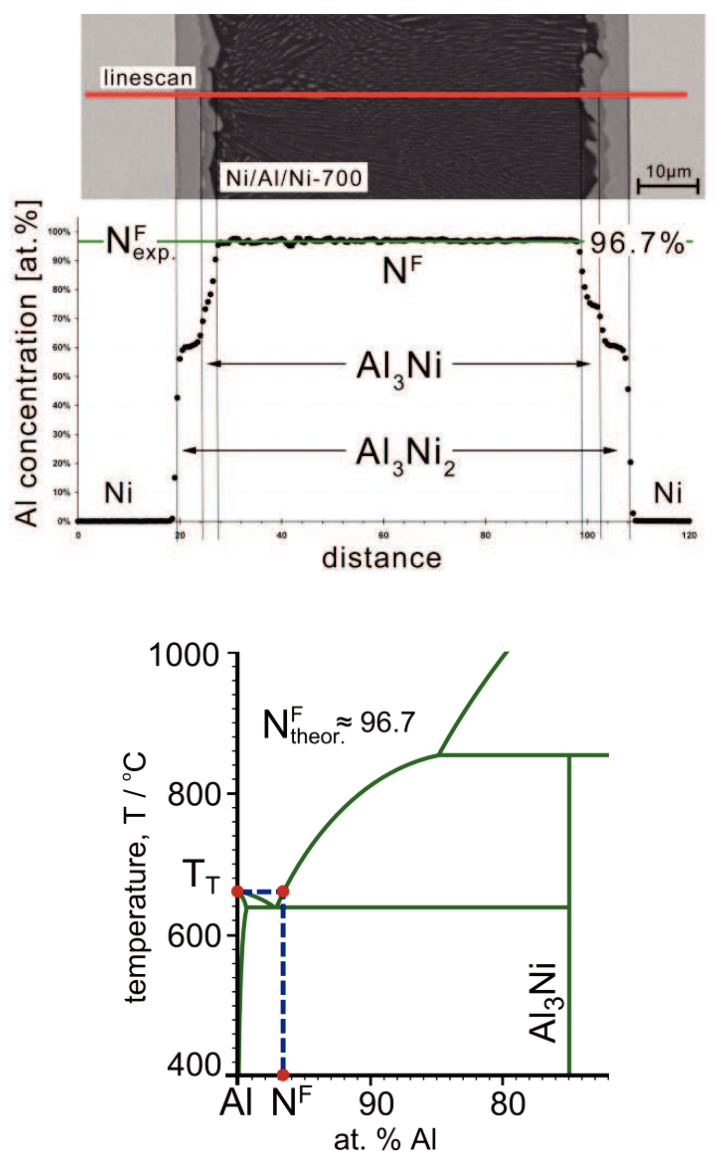

Figure 10. Method of determination of the $N^{F}$ - parameter: a/ experimentally with $\mathrm{Ni} / \mathrm{Al} / \mathrm{Ni}-700$ interconnection for which solidification was arrested and morphology frozen; $b /$ due to the Al-Ni meta-stable equilibrium phase diagram $\left(T_{T}\right.$ is the Al-melting point, $N^{F}$ - is the solution of the Ni in the Al-filler metal, as shown in Figure 1).

3/ The $N_{0}$ - solute concentration is created within the zone $d x$ as a result of dissolution, Figure 1-2.

4/ The $N_{0}-$ solute concentration is reproduced subsequently within the joint as an average solute concentration, Table 1.

5/ The $N_{0}$ - solute concentration created within the zone $d x$ corresponds well to the $N_{\min }$ - solute concentration which is manifested by the meta-stable equilibrium phase diagram for dissolution, Figure 8. It is evident that both parameters are equal to each other: $N_{0} \approx N_{\text {min }}$.

6/ The $N_{0}$ - solute concentration plays an essential role in the competition between stable and meta-stable formation of the interconnection, Figure 7.

7/ The $N_{0}$ - solute concentration located on the liquidus line, Figure 3, is treated as an initial condition for the differential equation which describes the solidification.

8/ According to the current model, creation of the zone $d x$, follows the reaction $N^{F}+N i \rightarrow s\left(N^{s}\right)+s s\left(N^{s s}\right)+$ $d x\left(N_{0}\right)$ as explained in Figure 11.

9/ According to the meta-stable equilibrium phase diagram, Figure 9, the first $\mathrm{Al}_{3} \mathrm{Ni}_{2}$ - intermetallic phase sub-layer (in sequence of appearance) is formed due to the phenomenon of partitioning along the solidification path $N_{0} \Rightarrow N_{2}^{M}$ and diffusion into the solid (it is marked in Figure 11).

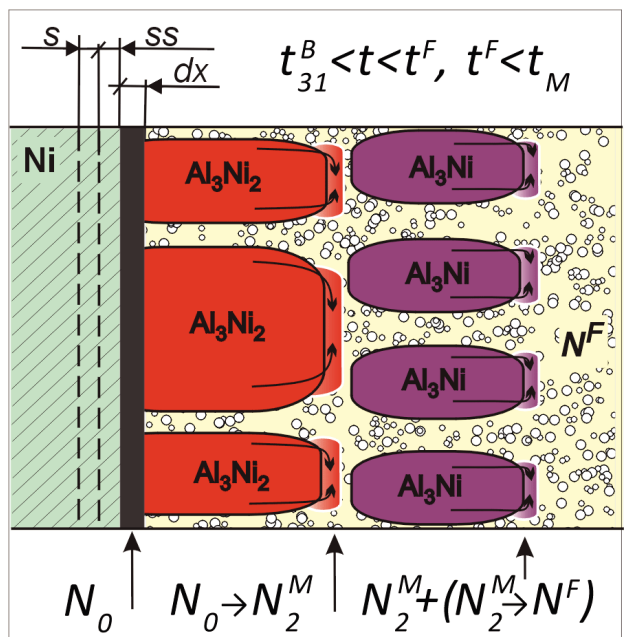

Figure 11. Localization of the zone $d x$, zone ss, and zone $s$ within the Ni-substrate.

10/ According to the same phase diagram, Figure 9, the second $\mathrm{Al}_{3} \mathrm{Ni}$ - intermetallic compound sub-layer is formed due to the interplay between the $N_{2}^{M}$ - liquid and $\mathrm{Al}_{3} \mathrm{Ni}_{2}$ primary phase. Next, due to the partitioning along the solidification path $N_{2}^{M} \rightarrow N^{F}$ with diffusion into the solid (it is marked in Figure 11).

11/ Localizations of the $N_{2}^{M}$ - liquid and $\mathrm{Al}_{3} \mathrm{Ni}_{2}$ primary phase in the growing joint suggests that the peritectic reaction (not peritectic transformation) takes place to form $\mathrm{Al}_{3} \mathrm{Ni}$ - compound at the $N_{2}^{M}$ - point, Figure 9 (according to the description by Phelan et al., 2006) (the occurrence of the peritectic reaction is marked in Figure 11).

12/ The Gibbs Phase Rule applied to the current model and experimental observations yields the Number of Degrees of Freedom $l=0$, as required for the isothermal solidification imposed to the joint technology, $l=c-p+1$. Thus $l=c-p+1=0$ with $c \equiv N i, A l$, and therefore $p=3$,

13/ In fact, $p \equiv \operatorname{liquid}\left(N_{0}\right)_{d x}, A l_{3} N i_{2}, A l_{3} N i=3$, as it is justified by the current model and adequate experiments, Figures 6 and 10a.

14/ The model is a universal one and can be applied to other situations where the brazing is expected.

$15 /$ It is suggested that brazing occurs in the case of massive rolls solidification, when the solid steel core interacts on the surrounding liquid cast iron added in the second step of the technology to improve the roll surface.

\section{Acknowledgements}

The financial support from the Polish Ministry of Science and Higher Education (MNiSW - Poland) under the contract: N R15 006004 is gratefully acknowledged.

\section{Nomenclature}

c number of elements which take part in a given reaction, (Gibbs Phase Rule),

$d x \quad$ infinitesimal amount of the substrate melted due to the dissolution of the liquid Al solute, [mole fr.],

$i \quad$ index of the range of solidification; $i=1$ for the range $N_{0} \Rightarrow N_{1} ; i=2$ for the range $N_{1} \Rightarrow N_{2}$; $i=3$ for the range $N_{2} \Rightarrow N^{F}$, Figure 3 , 
$k_{i} \quad$ partition ratio varying with the concentration of solute in the liquid, $i=1, \ldots, n$, [mole fr./mole fr.], first component of the partition ratio independent of any changes in the solute concentration along liquidus line, $i=1, \ldots, n$, [mole fr./mole fr.],

$k_{i}^{L} \quad$ second component of the partition ratio independent of any changes in the solute concentration along the liquidus line, $i=1, \ldots, n$, [mole fr./mole fr.],

$L^{0} \quad$ amount of the liquid at the start of solidification, usually $L^{0}=1$, [dimensionless],

$l$ Number of Degrees of Freedom for a given reaction, (Gibbs Phase Rule),

$l_{i}^{0} \quad$ amount of the liquid at the beginning of a given range of solidification, $i, i=1, \ldots, n$, [mole fr.],

$N_{i}^{B} \quad$ solute redistribution after partitioning and backdiffusion, $i=1, \ldots, n$, Eq. (5P), (5C), [mole fr.],

$N^{F} \quad$ concentration of the $\mathrm{Al}$ - filler metal in its liquid solution at the $T^{T}$ temperature, [mole fr.],

$N_{\text {exp. }}^{F} \quad$ concentration of the filler metal in its liquid solution at the $T^{T}$ temperature, determined experimentally, [mole fr.],

$N_{\text {theor. }}^{F} \quad$ concentration of the filler metal in its liquid solution at the $T^{T}$ temperature, determined theoretically, [mole fr.],

$N_{i}^{L} \quad$ solute concentration in the liquid, observed along the liquidus line for a given range of solidification, (local solidification path), $i=1, \ldots, n$, Eq. (1), Eq. (1P-3P), Eq. (1C-3C), [mole fr.],

$N_{i}^{S} \quad$ solute concentration at the solid / liquid interface, observed along the solidus line for a given range of solidification, (local solid/liquid interface path), $i=1, \ldots, n$, Eq. (4P), Eq. (4C), [mole fr.],

$N_{0} \quad$ solute content at the beginning of solidification path (on liquidus line), [mole fr.], also is the $\mathrm{Al}$ solute content within the zone $d x$, created at the substrate surface by the dissolution phenomenon,

$\widehat{N}_{0} \quad$ average solute concentration measured across the formed multi-layer, [mole fr.],

$\overline{N_{0}}$ average solute concentration within the all investigated joints, [mole fr.],

$N_{1} \quad$ solute concentration in the liquid at the first peritectic reaction (phase diagram for stable equilibrium), Figure 3, [mole fr.],

$N_{2} \quad$ solute concentration in the liquid at the second peritectic reaction (phase diagram for stable equilibrium), Figure 3, [mole fr.],

$N_{2}^{M} \quad$ solute concentration in the liquid at the peritectic reaction (phase diagram for the meta-stable equilibrium), Figure 9, [mole fr.],

$N_{i} \quad$ solute concentration in the liquid at a given peritectic reaction (phase diagram for stable equilibrium), Figure 3, Eq. (2), $i=1,2$, [mole fr.],

$N_{i-1}$ solute concentration in the liquid at a given peritectic reaction, (for $i=2,3$ ) or solute concentration at the beginning of solidification path (for $i=1$ ), (phase diagram for stable equilibrium), Eq. (1), Figure 3, [mole fr.],

$N^{s} \quad$ solute concentration within the zone $s$, (Figure 9), [mole fr.],

$N^{s s} \quad$ solute concentration within the zone ss, (Figure 9), [mole fr.],
$N_{\min }$

\section{$n$}

$n$ number of ranges of solidification for a given solidification path, $n=3$,

$p$ number of phases which take part in a given reaction, (Gibbs Phase Rule),

$S \quad$ zone of saturation created in the substrate,

ss zone of super-saturation created in the substrate,

$T_{f}^{*} \quad$ temperature at the solid / liquid interface of a given phase / compound, $f$,

$f \equiv A l N i, A l_{3} N i_{2}, A l_{3} N i$, (shortly, $f \equiv 11,32,31$ )

as it results from the intersection of a given metastable solidus line with the line which denotes $N_{0}$ concentration, $[\mathrm{K}]$,

$T_{11}^{*} \quad$ temperature of the AlNi phase solid /liquid interface, Figure 7, [K],

$T_{32}^{*}$ temperature of the $\mathrm{Al}_{3} \mathrm{Ni}_{2}$ phase solid /liquid interface, Figure 7, [K],

$T_{D} \quad$ temperature at which the minimum of liquidus line appears in the phase diagram for meta-stable equilibrium, Figure $8,[\mathrm{~K}]$,

$T_{R} \quad$ real temperature of bonding (temperature of the interconnection formation), $[\mathrm{K}]$,

melting temperature of the $\mathrm{Al}$ - filler metal, [K], time of the solidification progress, Figure 5a, [s],

$t^{K}$

$t^{F}$

$t$

5b, Figure 11, [s],

time, $[\mathrm{s}]$,

time of the beginning of the first solid / solid transformation, Figure 11, [s],

$t_{31}^{B} \quad$ time of the birth of the $\mathrm{Al}_{3} \mathrm{Ni}$ phase within the $\mathrm{Ni} / \mathrm{Al} / \mathrm{Ni}$ interconnection, Figure 11, [s],

$X^{0} \quad$ amount of the solid at a given stage (progress) of solidification when the process is arrested and morphology frozen (calculated for a total system along a global solidification path) [dimensionless],

$x \quad$ current amount of the solid, [dimensionless],

$x_{i} \quad$ amount of the primary phase which takes part in a given peritectic reaction at the $i-t h$ range of solidification, $i=1, \ldots, n$, [dimensionless],

$x_{i}^{0} \quad$ amount of the solid at a given stage (progress) of solidification when the process is arrested and morphology frozen, (calculated for a given $i-t h$ range of solidification along a local solidification path), [dimensionless],

$x_{i}^{\max } \quad$ sum of amounts of both primary phase remaining after peritectic reaction and peritectic phase resulting from the peritectic reaction for a given solidification range, $i=1, \ldots, n$, [dimensionless],

$x_{i}^{\text {min }}$ amount of the primary phase remaining after the peritectic reaction for a given solidification range, $i=1, \ldots, n$, [dimensionless];

$x_{i}^{\max }-x_{i}^{\min }$

denotes the amount of peritectic reaction product obtained for a given solidification range, $i=$ $1, \ldots, n, \quad$ [dimensionless]; a peritectic reaction which occurs at the $N_{i}$ solute concentration (on liquidus) is treated as belonging to the $i-t h$ solidification range, (phase diagram for the stable equilibrium),

$\alpha_{i}^{D} \quad$ back-diffusion parameter for both partitioning and redistribution, $i=1, \ldots, n$, [dimensionless], 
redistribution extent coefficient, $i=1, \ldots, n$, (defined in detail by Wołczyński et al. 2006a), [dimensionless],

$\beta_{i}^{\text {in }}$ redistribution intensity coefficient, $i=1, \ldots, n$, (defined in details by Wołczyński et al. 2006a), [dimensionless],

$\lambda_{1}^{F}$ thickness of the $\mathrm{Al}_{3} \mathrm{Ni}_{2}$ phase sub-layer within the interconnection formed at time $t^{F}$, Figure 5, [ $\left.\mu \mathrm{m}\right]$, $\lambda_{2}^{F} \quad$ half the thickness of the $\mathrm{Al}_{3} \mathrm{Ni}$ phase sub-layer within the interconnection formed at time $t^{F}$, Figure 5, $[\mu \mathrm{m}]$,

$\lambda_{1}^{K}$ thickness of the $\mathrm{Al}_{3} \mathrm{Ni}_{2}$ phase sub-layer within the interconnection formed at time $t^{K}$, Figure 5, [ $\left.\mu \mathrm{m}\right]$,

$\lambda_{2}^{K} \quad$ half the thickness of the $\mathrm{Al}_{3} \mathrm{Ni}$ phase sub-layer within the interconnection formed at time $t^{K}$, Figure 5, $[\mu \mathrm{m}]$.

\section{Appendix}

The following mathematical formalism is applied for:

$1 /$ formation of the intermetallic phase

The solute concentration in the liquid, changes during precipitation of primary phases along a given local solidification path, $i$, in accordance with the relationship:

$$
\begin{aligned}
& N_{i}^{L}\left(x ; \alpha_{i}^{D}, l_{i}^{0}, N_{i-1}, k_{i}^{0}\right) \\
& \quad=N_{i-1}\left[\left(l_{i}^{0}+\alpha_{i}^{D} k_{i}^{0} x-x\right) / l_{i}^{0}\right]^{\frac{k_{i}^{0}-1}{1-\alpha_{i}^{D} k_{i}^{0}}}
\end{aligned}
$$

The Eq. (1P) is the solution to differential equation:

$d N_{i}^{L} / d x=\left(1-k_{i}^{0}\right) N_{i}^{L} /\left(l_{i}^{0}+\alpha_{i}^{D} k_{i}^{0} x-x\right)$

with the initial condition:

$N_{i}^{L}\left(0 ; \alpha_{i}^{D}, l_{i}^{0}, N_{i-1}, k_{i}^{0}\right)=N_{i-1}$

The phenomenon of partitioning results in the formation of the solid / liquid interfaces, and "history" of the solute concentration at the existed interfaces are given as:

$N_{i}^{S}\left(x ; \alpha_{i}^{D}, l_{i}^{0}, N_{i-1}, k_{i}^{0}\right)=k_{i}^{0} N_{i}^{L}\left(x ; \alpha_{i}^{D}, l_{i}^{0}, N_{i-1}, k_{i}^{0}\right)$

The phenomenon of back-diffusion superposes solute partitioning.

The superposition of both phenomena results in the solute redistribution, which is a function of the solute concentration at formerly existing solid / liquid interfaces.

$$
\begin{gathered}
N_{i}^{B}\left(x ; x_{i}^{0}, \alpha_{i}^{D}, l_{i}^{0}, N_{i-1}, k_{i}^{0}\right)=N_{i}^{S}\left(x ; \alpha_{i}^{D}, l_{i}^{0}, N_{i-1}, k_{i}^{0}\right) \\
\times\left[1+\beta_{i}^{e x}\left(x ; x_{i}^{0}, l_{i}^{0}, k_{i}^{0}\right) \beta_{i}^{i n}\left(x_{i}^{0}, \alpha_{i}^{D}, l_{i}^{0}, k_{i}^{0}\right)\right]
\end{gathered}
$$

2/ formation of the intermetallic compound

The solute concentration in the liquid changes during precipitation of primary phases along a given solidification path, $i$, in accordance with the following relationship:

$$
\begin{aligned}
& N_{i}^{L}\left(x ; \alpha_{i}^{D}, l_{i}^{0}, N_{i-1}, k_{i}\right)=\left[N_{i-1} /\left(1-k_{i}^{0}\right)\right] \\
& \quad \times\left\{k_{i}^{L}+\left(1-k_{i}^{0}-k_{i}^{L}\right)\left[\left(l_{i}^{0}+\alpha_{i}^{D} k_{i}^{0} x-x\right) / l_{i}^{0}\right]^{\frac{k_{i}^{0}-1}{1-\alpha_{i}^{D} k_{i}^{0}}}\right\}
\end{aligned}
$$

Eq. (1C) is the solution to differential equation for solidification/micro-segregation: $d N_{i}^{L} / d x=\left[\left(1-k_{i}^{0}\right) N_{i}^{L}-k_{i}^{L} N_{i-1}\right] /\left(l_{i}^{0}+\alpha_{i}^{D} k_{i}^{0} x-x\right)$

with the initial condition:

$N_{i}^{L}\left(0 ; \alpha_{i}^{D}, l_{i}^{0}, N_{i-1}, k_{i}^{0}, k_{i}^{L}\right)=N_{i-1}$

The "history" of solute concentration, at the appearing interfaces is described as follows:

$$
\begin{aligned}
& N_{i}^{S}\left(x ; \alpha_{i}^{D}, l_{i}^{0}, N_{i-1}, k_{i}\right)=k_{i}^{0} N_{i}^{L}\left(x ; \alpha_{i}^{D}, l_{i}^{0}, N_{i-1}, k_{i}\right) \\
& \quad+k_{i}^{L} N_{i-1}
\end{aligned}
$$

Consequently, the solute redistribution after partitioning and back-diffusion is given by:

$$
\begin{gathered}
N_{i}^{B}\left(x ; x_{i}^{0}, \alpha_{i}^{D}, l_{i}^{0}, N_{i-1}, k_{i}\right)=N_{i}^{S}\left(x ; \alpha_{i}^{D}, l_{i}^{0}, N_{i-1}, k_{i}\right) \\
\quad \times\left[1+\beta_{i}^{e x}\left(x ; x_{i}^{0}, l_{i}^{0}, k_{i}\right) \beta_{i}^{i n}\left(x_{i}^{0}, \alpha_{i}^{D}, l_{i}^{0}, k_{i}\right)\right]
\end{gathered}
$$

All the relationships are formulated with:

$l_{i}^{0}=\left\{\begin{array}{c}L^{0}, \quad i=1 ; \\ L^{0}-\sum_{j=1}^{i-1} x_{j}^{\text {max }}, i=2, \ldots, n ;\end{array}\right.$

$$
x_{i}^{0}=\left\{\begin{array}{c}
X^{0}, \quad i=1 ; \\
X^{0}-\sum_{j=1}^{i-1} x_{j}^{\max }, i=2, \ldots, n ;
\end{array}\right.
$$

Additionally, the coefficient of the redistribution extent $\beta_{i}^{e x}\left(x ; x_{i}^{0}, l_{i}^{0}, k_{i}\right)$ is the solution to the following equation:

$\left(1+\beta_{i}^{e x}\right) N_{i}^{S}\left(x ; 1, l_{i}^{0}, N_{i-1}, k_{i}\right)=N_{i}^{S}\left(x_{i}^{0} ; 1, l_{i}^{0}, N_{i-1}, k_{i}\right)$

Moreover, the definition of the coefficient of the redistribution intensity was also formulated.

The $\beta_{i}^{i n}\left(x_{i}^{0} ; \alpha_{\mathrm{i}}^{\mathrm{D}}, l_{i}^{0}, k_{i}\right)$ - coefficient of the redistribution intensity is a result of the solution to the equation:

$$
\begin{gathered}
\int_{0}^{x_{i}^{0}}\left[1+\beta_{i}^{\text {in }} \beta_{i}^{e x}\left(x ; x_{i}^{0}, l_{i}^{0}, k_{i}\right)\right] N_{i}^{S}\left(x ; \alpha_{i}^{D}, l_{i}^{0}, k_{i}\right) d x \\
\quad=l_{i}^{0} N_{i-1}-\left(l_{i}^{0}-x_{i}^{0}\right) N_{i}^{L}\left(x_{i}^{0} ; \alpha_{i}^{D}, l_{i}^{0}, N_{i-1}, k_{i}\right)
\end{gathered}
$$

\section{References}

Chuang, Y.K., Reinisch, D. \& Schwerdtfeger, K. (1975). Kinetics of Diffusion Controlled Peritectic Reaction During Solidification of Iron-Carbon Alloys, Metallurgical Transactions, 6(A), 235-238.

Kloch, J., Guzik, E., Janczak-Rusch, J., Kopyciński, D., Rütti, T., Kim, J., Lee, H.M. \& Wołczyński, W. (2005). Morphological Characteristics of the Multilayer/Substrate Systems, Proceedings of the $9^{\text {th }}$ European Congress on Stereology and Image Analysis, Zakopane (Poland), 375-382.

Jacobson, D.M. \& Humpston, G. (1992). Diffusion Soldering, Soldering \& Surface Mount Technology,10, 27-32.

Tuah-Poku, I., Dollar, M. \& Massalski, T. (1988). A Study of the Transient Liquid Phase Bonding Process Applied to a $\mathrm{Ag} / \mathrm{Cu} / \mathrm{Ag}$ Sandwich Joint, Metallurgical Transactions, 19A, 675-686. 
Umeda, T., Okane, T. \& Kurz,W. (1996), Phase Selection during Solidification of Peritectic Alloys, Acta Materialia, 44, 4209-4216.

Wołczyński, W., Guzik, E., Kopyciński, D., Himemiya, T. \& Janczak-Rusch, J. (2006a). Mass Transport during Diffusion Soldering or Brazing at the Constant Temperature, Proceedings of the $13^{\text {th }}$ International Heat Transfer Conference - Sydney (Australia), ed. Begell House, eds. G.de Vahl Davis \& E.Leonardi, CD, MST11, 12 pages.
Wołczyński, W., Kloch, J., Janczak-Rusch, J., Kurzydłowski, K. \& Okane, T. (2006b). Segregation Profiles in Diffusion Soldered Ni/Al/Ni Interconnections, Materials Science Forum, 508, $385-$ 392 .

Phelan, D., Reid, M. \& Dippenaar, R. (2006), Kinetics of the Peritectic Phase Transformation: In-situ Measurements and Phase Field Modelling, Metallurgical and Materials Transactions, 37A, 985994. 